\title{
Brachial Plexus Injury in Abdominal and Breast Surgery
}

\author{
Eyüp Murat Yilmaz ${ }^{1 *}$ and Ethem Bilgiç ${ }^{2}$ \\ ${ }^{1}$ Department of General Surgery, Adnan Menderes University, Turkey \\ ${ }^{2}$ Department of general surgery, Bozyaka Training and Research Hospital, İzmir, Turkey \\ *Corresponding author: Eyüp Murat Yılmaz, Department of General Surgery, Faculty of Medicine, Adnan Menderes University, Aydin, Turkey
}

Submission: 12 July, 2018; Published: August 21, 2018

\begin{abstract}
Brachial plexus injury is a picture of the upper extremity that leads to numbness, pain, and limitation of movement, usually seen in newborns and trauma cases. Iatrogenically, it is observed after thorax, orthopedics, breast, and abdominal surgeries nevertheless it is quite rare. Risk factors exist and treatment and management seem to be a challenging clinical condition.
\end{abstract}

Keywords: Brachial plexus; Abdominal surgery; Breast surgery; Nerve injury

\section{Introduction}

Brachial plexus injury is a case of a motion disorder and pain in the upper extremity that causes functional limitation and serious financial stress in the community and in the patient $[1,2]$. The incidence of brachial plexus injuries was reported to be approximately $0.2 \%$ in all patients who underwent general anesthesia [3]. The majority of iatrogenic injuries develop after heart, orthopedic, breast, and abdominal surgery [4]. Although the mechanism is not clearly known, it is known that the abduction angle more than 90 degrees during the operation on the cord, the low elbow level, the erroneous placement of the shoulder supports in the surgery, the long-term stay in the trendelenburg position, diagnosis of diabetes mellitus in the patient and low body temperature are known to be as risk factors [5,6]. Alcoholism, vitamin B12 deficiency, smoking history, prolonged anesthesia and obesity are also predisposing factors [7]. In this section, we will refer to the injuries of the brachial plexus that develop in abdominal and breast surgery.

\section{Abdominal Surgery}

The brachial plexus is formed from the ventral rami of the lower cervical and upper thoracic nerve roots. These are divided into bodies, parts, cords, and branches. There are some studies in the literature demonstrating that prolonged trendelenburg positions increase brachial plexus damages in abdominal surgeries, especially with shoulder stabilizers. Especially in pelvic surgery, the trendelenburg position provides a good exposure for surgeons. Mi Young et al. [8] reported that a prolonged trendelenburg position in laparoscopic colorectal surgery poses a risk for brachial plexus injury [8]. Yet, another mechanism is the compression of the humerus head by the first rib and the clavicle. These mechanisms are particularly common in laparoscopic and robotic situations $[7,9]$. The increasing popularity and widespread use of advanced laparoscopy and robotic surgery among general surgeons and urologists in the last decade have also been one of the factors increasing this risk. Cheney et al. [10] found that eight cases of 83 brachial plexus injuries reported between 1990-1995 were associated with intraoperative patient placement. In four of these cases, it has been put forward that shoulder restraint was used in the trendelenburg position, that three cases originated from the improper positioning of the arm, and that one case originated from the prolongation of the neck. In addition, many cases of brachial plexus risk factors in abdominal surgeons have been investigated. Hida et al. [11] have found that relatively common neurological injuries during liver transplantation, brachial plexus injury, have been associated with surgical procedures such as prolonged anesthesia, invasive central venous catheter, and veno-venous bypass and thoracic cage retraction. Apart from this, there are many studies in the literature reporting that brachial plexus damage in abdominal cases may happen especially in pelvic and gynecological cases too [12].

\section{Breast Surgery}

There are recent studies reporting that the brachial plexus, rarely known to be iatrogenically injured due to stress and position at the time of surgery in breast and axilla surgeons, is up to $9 \%$ $[13,14]$. Although the mechanism is not fully explained, it is believed that the position at the time of surgery contributes to the 
injury of the plexus [15]. Extreme abduction and upward stretching movements on the upper extremity contribute to injury in this mechanism. This mechanism can occur when extreme traction is applied to provide a good exposure during surgeries such as axillary dissection, latissumus dorsi flap. In addition, radiosurgery after breast surgery may have a considerable effect on brachial plexus injury $[16,17]$.

The famous British neuroscientist Victor Horseley described the compression and stretching mechanism after Budinger identified the brachial plexus injury in the breast surgery as a surgical complication in 1894 and attributed it to the toxic effect of chloroform $[13,18]$. According to this, during the operation, the nerve is first made sensitive to damage by the surgeon with the superficial position. Then the nerve roots, the proximal part, the muscles, the faeces and the part to which the distal is connected are fixed, so that the force exerted by the surgeon will damage the nerve. Finally, Due to the narrow space between the clavicle and 1 st costa, the pressure applied here can damage the nerve $[13,19]$.

\section{Symptoms in Brachial Plexus Injury}

Brachial plexus injuries seen in adults are associated more with traumatic injuries [traffic accidents, etc.] compared with iatrogenic injuries [20] Clinical findings may be more severe in traumatic ones, but more mild symptoms may be seen in iatrogenic ones. Since C5$\mathrm{T} 1$ interval is related to invasion, there may be abduction in arm and flexion loss in the cord during C6-C6 injuries [20,21]. Rarely seen hand function reductions indicate a damage in C8T1 [20]. Sensory loss is a very important finding. The sensory examination in this dermatome's area must be performed effectively. Besides that, stubborn pain and dry skin can also be important symptoms.

\section{Diagnosis}

The clinician should be suspicious in patients who have had breast and abdominal surgery and have specific symptoms. Physical examination is the first procedure that must be performed in diagnosis. Especially abduction and limitation of flexion in the upper extremity and sensory loss in this dermatome area should be investigated [22]. Besides, electromyography [EMG] and Axon reflex tests may be helpful in diagnosis $[13,22]$. At the same time, EMG can give an idea of whether the injury is acute or chronic [23].

Electrophysiological studies can detect changes in nerve function in the perioperative period, however, there is a lack of spacious prospective studies demonstrating the importance of electrophysiological studies in the early diagnosis of brachial plexus neuropathy [22].

MR-neurography is accepted as the best imaging method today for imaging the plexus radiologically if there is a direct ligation to the sinus during surgery or by accident [24].

\section{Treatment}

It is important that the surgeon protects the plexus well in advance rather than the treatment of iatrogenic injuries. It is important to place the position of the upper extremity properly during surgery to reduce the risk to the minimum [25]. Excessive abruption, extension, and external rotation should be avoided, if possible, the case should be in the neutral position, extension of the cases made with the trendelenburg position, extension of the general anesthesia duration and hypothermia during the operation should be avoided. If nerve damage occurs despite the best precautions, conservative treatment is recommended for approximately 3 weeks if there is no vascular damage and compartment syndrome [4]. In the meantime, nonsteroidal anti-inflammatory drugs such as gabapentin, carbamazepine can be effective. There are studies showing that adding antidepressants to these types of antiepileptic drugs reduces persistent pain by $30 \%$ [26]. Some authors have reported the duration of this denervation as 3 months. [27]. The repair of the brachial plexus injury has progressed significantly due to the technological advances of the 20th and 21st centuries compared to the last 50 years. The timing of the surgery is very important. Expected duration of healing, especially in upper plexus injuries, should not exceed three months [20]. For patients, who can not be denervated after appropriate time with physical therapy and conservative treatment, with proven EMG record, one of the appropriate procedures should be selected such as intra-plexal repair, extra plexy repair, distal nerve transfer, and reconstruction [20].

As a result, although brachial plexus injury is rarely seen in abdominal and breast surgeons, surgeons should be vigilant and careful in this regard and should cooperate with the relevant clinics in the management of this issue.

\section{References}

1. Dengler NF, Antoniadis G, Grolik B, Wirtz CR, König R, et al. (2017) Mechanisms, treatment, and patient outcome of latrogenic injury to the brachial plexus-a retrospective single-center study. World Neurosurg 107: 868-876

2. Santana MV, Bina MT, Paz MG, Santos SN, Teixeira MJ, et al. (2016) High prevalence of neuro pathicpain in the hand of patients with traumatic brachial plexus injury: a cross-sectional study. Arq Neuropsiquiatr 74(11): 895-901.

3. Birch R, Bonney G, Dowell J, Hollingdale J (1991) Iatrogenic injuries of peripheral nerves. J Bone Joint Surg Br 73(2): 280-282.

4. Daga G, Kerkar PB (2017) Brachial plexus injury after right hepatectomy. Indian J Surg Oncol 8(2): 191-194.

5. Elhassan BT, Wagner ER, Spinner RJ, Bishop AT, Shin AY (2016) Contralateral trapezius transfer to restore shoulder external rotation following adult brachial plexus injury. J Hand Surg Am 41(4): e45-e51.

6. Song J (2012) Severe brachial plexus injury after retropubic radical prostatectomy. Korean J Anesthesiol 63(1): 68-71.

7. Shveiky D, Aseff JN, Iglesia CB (2010) Brachial plexus injury after laparoscopic and robotic surgery. J Minim Invasive Gynecol 17(4): 414420.

8. Min Young N, Jae Moon S, Won Jun C (2013) Two cases report of brachial plexus injury in laparoscopic colorectal surgery. Korean J Anesthesiol 65(6 Suppl): 149-150.

9. Akhavan A, Gainsburg DM, Stock JA (2010) Complications associated with patient positioning in urologic surgery. Urology 76(6): 1309-1316. 
10. Cheney FW, Domino KB, Caplan RA, Posner KL (1999) Nerve injury associated with anesthesia: a closed claims analysis. Anesthesiology 90(4): 1062-1069.

11. Hida A, Arai T, Nakanishi K, Nagaro T (2008) Bilateral brachial plexus injury after liver transplantation. J Anesth 22(3): 308-311.

12. Kuponiyi O, Alleemudder A, Latunde-Dada A, Eedarapalli P (2014) Nerve injuries associated with gynaecological surgery. The Obstetrician \& Gynaecologist 16(1): 29-36.

13. Wu JD, Huang WH, Huang ZY, Chen M, Zhang GZ (2013) Brachial plexus palsy after a left-side modified radical mastectomy with immediate latissimus dorsi flap reconstruction: report of a case. World J Surg Oncol 11: 276.

14. Dubuisson AS, Kline DG (2002) Brachial plexus injury: a survey of 100 consecutive cases from a single service. Neurosurgery 51(3): 673-682.

15. Grunwald Z, Moore JH, Schwartz GF (2003) Bilateral brachial plexus palsy after a right-side modified radical mastectomy with immediate TRAM flapre construction. Breast J 9(1): 41-43.

16. Ng K, KL C (1999) Brachial plexus injury occurring during breast surgery Ann Coll Surg 3(3): 91-93.

17. Wilkinson S, Chetty U, Forrest AP (1985) Operative aid to combined synchronous mastectomy and latissimus dorsi breast reconstruction. Aust N Z J Surg 55(6): 585-587.

18. Horseley V (1899) On injuries to peripheral nerves. Practitioner 63: 131-144

19. Kirsh MM, Magee KR, Gago O, Kahn DR, Sloan H (1971) Brachial plexus injury following median sternotomy incision. Ann Thorac Surg 11(4): 315-319.
20. Thatte MR, Babhulkar S, Hiremath A (2013) Brachial plexus injury in adults: Diagnosis and surgical treatment strategies. Ann Indian Acad Neurol 16(1): 26-33.

21. Gu YD, Zhang GM, Chen DS, Yan JG, Cheng XM, et al. (1992) Seventh cervical nerve root transfer from the contralateral healthy side for treatment of brachial plexus root avulsion. J Hand Surg Br 17(5): 518521.

22. Sharma AD, Parmley CL, Sreeram G, Grocott HP (2000) Peripheral nerve injuries during cardiac surgery: risk factors, diagnosis, prognosis and prevention. Anesth Analg 91(6): 1358-1369.

23. Desai KR, Nemcek AA (2011) Latrogenic brachial plexopathy due to improper positioning during radiof requency ablation. Semin Intervent Radiol 28(2): 167-170.

24. Amrami KK, Port JD (2005) Imaging the brachial plexus. Hand Clin 21: 25-37.

25. Winfree CJ, Kline DG (2005) Intra operative positioning nerve injuries. Surg Neurol 63(1): 5-18.

26. Sakellariou VI, Badilas NK, Stavropoulos NA, Mazis G, Kotoulas HK, et al. (2014) Treatment options for brachial plexus injuries. ISRN Orthop.

27. Ferrante MA (2012) Electro diagnostic assessment of the brachial plexus. Neurol Clin 30(2): 551-580.
Creative Commons Attribution 4.0 International License

For possible submissions Click Here

\section{Submit Article}

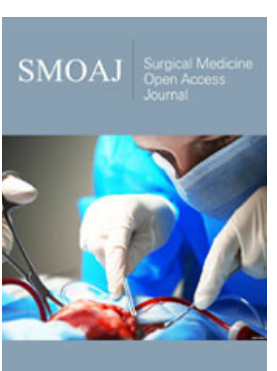

Surgical Medicine Open Access Journal

\section{Benefits of Publishing with us}

- High-level peer review and editorial services

- Freely accessible online immediately upon publication

- Authors retain the copyright to their work

- Licensing it under a Creative Commons license

- Visibility through different online platforms 